Retrospective Analysis

\title{
A Contemporary Medicolegal Analysis of Injury Related to Peripheral Nerve Blocks
}

Ramsey Saba, MD1, Ethan Y. Brovman, MD¹,3, Daniel Kang, MD1, Penny Greenberg, RN², Alan D. Kaye, MD, $\mathrm{PhD}^{4}$, and Richard D. Urman, $\mathrm{MD}^{1,3}$

From: ${ }^{1}$ Department of Anesthesiology, Perioperative and Pain Medicine, Brigham and Women's Hospital, Harvard Medical School, Boston, MA; ${ }^{2} \mathrm{CRICO}$ Strategies, Boston, MA ${ }^{3}$ Center for Perioperative Research, Brigham and Women's Hospital, Boston, MA; ${ }^{4}$ Department of

Anesthesiology, Louisiana

State University Health

Sciences Center, New

Orleans, LA

Address Correspondence: Richard D. Urman, MD Department of Anesthesiology, Perioperative and Pain Medicine

Brigham and Women's Hospital/Harvard Medical School 75 Francis St. Boston, MA 02115 E-mail:

rurman@bwh.harvard.edu

Disclaimer: There was no external funding in the preparation of this manuscript.

Conflict of interest: Each author certifies that he or she, or a member of his or her immediate family, has no commercial association

(i.e., consultancies,

stock ownership, equity interest, patent/licensing arrangements, etc.) that

might pose a conflict of interest in connection with the submitted manuscript.

Manuscript received: 12-02-2018

Revised manuscript received: o1-14-2019 Accepted for publication: 01-22-2019

Free full manuscript: www.painphysicianjournal.

com
Background: Closed malpractice claims can provide insight into low-frequency adverse events in many areas of perioperative and chronic pain care. Over the last decade, there have been changes in surgical and regional anesthetic practice, likely impacting adverse event patterns. Given the wide variability and low frequency of complications associated with peripheral nerve blocks, the study of closed malpractice claims offers an opportunity to examine adverse events, and the patient, technical, and provider factors that led to the claim. Knowledge gained from examination of closed claims has already resulted in multiple improvements in processes of care and patient safety.

Objectives: An investigation of the factors that contributed to medicolegal claims against anesthesia providers related to peripheral nerve blocks.

Study Design: Retrospective analysis.

Setting: Inpatient and outpatient surgery facilities.

Methods: The Comparative Benchmarking System database is a medical liability database that contains more than 400,000 malpractice claims from more than 400 academic and communitybased institutions accounting for over $30 \%$ of malpractice claims in the United States. The present investigation reviewed all $(n=113)$ available closed malpractice claims related to regional anesthesia (RA) in surgical patients closed between 2006 and 2016, and investigated factors that may have contributed to patient injury, including type of nerve block, type of surgery, nerves injured, resulting neurologic deficits, and potential factors contributing to the injury.

Results: Our data analyzed 62 claims related to RA and showed that most closed claims were classified as permanent minor injuries. The greatest number of claims were for brachial plexus injuries associated with interscalene blocks performed for shoulder or rotator cuff repairs. Femoral and sciatic nerve blocks with resulting lower extremity injuries were the most common nerve blocks resulting in payment. The largest contributing factor to these injuries was noted to be "Technical Knowledge/Performance" of the regionalist followed by "Pre-existing Injury/Radiculopathy." Symptom onset from these claims was most likely to be delayed with the leading initial presenting symptom being paresthesia.

Limitations: It is difficult to establish cause-effect relationship, and the small sample size limits the ability to detect clinical differences and associations with specific comorbidities or techniques. There was also limited information related to regional anesthetic techniques and medications used that would have helped explore further relationships between the procedure and cause for litigation.

Conclusions: There remains significant room for risk reduction in regional anesthetic practice. Patterns based on the analysis of closed claims show that interscalene blocks are the most common peripheral nerve block resulting in litigation, even when compared with other blocks involving the brachial plexus. Furthermore, patients with existing nerve injury/radiculopathy may also warrant alternative techniques or greater emphasis during informed consent on the increased risk of injury. As most of the presenting symptoms associated with claims are delayed, an opportunity for improvement in postregional care may be better communication with patients following discharge to discuss their postoperative recovery.

Key words: Regional, pain, anesthesia, complications, closed claims, liability, nerve, block, injury

Pain Physician 2019: 22:389-399 
T here has been a growing interest in acute and chronic pain management, including in orthopedics and other surgical and medical fields that use regional anesthesia (RA) techniques. RA with ultrasound guidance has been linked to a favorable perioperative profile including improvements in pain management, decreased opioid requirements, reduced risk of nausea and vomiting, and shorter time to discharge (1).

Clinical registry data can provide insight into the epidemiology of RA usage. One study of total knee arthroplasties from 2010 to 2013 in the Anesthesia Quality Institute National Anesthesia Clinical Outcomes Registry showed that $11 \%$ were performed with peripheral nerve blocks alone (2). Review of the Premier Perspective Inc. Registry from 2007 to 2011 showed that $15.4 \%$ of surgical rotator cuff repairs were performed under peripheral nerve blocks in addition to general anesthesia (3).

As RA has grown in popularity, there has been a concurrent expansion of approaches to performing these blocks including anatomic, nerve-stimulating, and/or ultrasound-guided techniques (4). Upper extremity surgery and pain states, for instance, may benefit from an interscalene, supraclavicular, infraclavicular, or axillary block, each with its own safety profile and clinical use (5). Furthermore, there are many needle types, local anesthetics, and adjunct medications a clinician can choose from when performing these blocks. Given the wide variability in these employed techniques and equipment used, there is also variability in the associated complications.

The incidence of irreversible nerve damage after peripheral nerve blocks has been cited at $0.3 \%$. Reversible deficits, however, occur more frequently, with a reported incidence of $3 \%$ to $8 \%$ (6).

It is often difficult to identify a single causative factor leading to these injuries as their cause is likely multifactorial (4). However, although multiple factors may be associated with nerve injury, targeted studies may lead to prevention strategies that can reduce that risk $(2,7)$.

Given the wide variability and low frequency of complications associated with RA, the study of closed malpractice claims offers an opportunity to examine adverse events and the patient, technical, and provider factors that led to the claim. Knowledge gained from examination of closed claims has already resulted in multiple improvements in processes of care and patient safety in the perioperative setting and chronic pain management $(7,8)$. A study by Lee et al $(9)$ using the American Society of Anesthesiologists Closed Claims Database examined complications associated with peripheral nerve blocks occurring between 1990 and 2010. It showed that most injuries (38\%) involved brachial plexus blocks. Since this study, there have been no further closed claims studies of RA. Another more recent systematic review by Chui et al (10) examined peripheral nerve injuries from 1990 to 2013 and found that peripheral nerve injuries comprised $12 \%$ of all general anesthesia claims, with two-thirds being injuries to the ulnar or the brachial plexus nerves. Although the authors used more recent data relating to peripheral nerve injuries, there was no discussion or delineation of the cause of injury as related to a wide variation of regional techniques.

The present study examines closed claims associated with RA. We hypothesized that our contemporary cohort would offer more insight than any of the previous studies into the causes and factors associated with injury after RA, perhaps yielding new injury patterns as technological and pharmacological advances continue to improve the safety of RA.

\section{Methods}

The present investigation used data from the Controlled Risk Insurance Company (CRICO) that was formed in 1976 by the hospitals in the Harvard Medical School system. CRICO provides both claims management and patient safety innovation (8). To improve patient care and risk management, CRICO Strategies developed the Comparative Benchmarking System (CBS) database, which contains more than 400,000 malpractice claims from hospitals insured by CRICO and more than 400 additional academic and community institutions. The CBS includes both captive and commercial insurers, and accounts for over $30 \%$ of malpractice claims in the United States (11). Cases reported to the CBS are not reported to the Anesthesia Closed Claims Project. The study was approved by Partners Healthcare institutional review board and written consent was waived given the retrospective, deidentified nature of the study.

We performed a retrospective review of all $(n=$ 113) malpractice claims related to RA closed between 2006 and 2016. We assessed for various factors contributing to the claim. Each claim file contained a narrative summary that included patient comorbidities, type of surgery, injury course, the type of block performed, specific complications, case disposition (settled/dismissed), indemnity amount, and the National Association of 
Insurance Commissioners (NAIC) severity code. The NAIC code was developed to be a simple method ranking injuries from 1 to 9 for increasing severity, as seen in Table 1. It is common practice to set investigative priorities on newly opened claims by assigning them a NAIC severity code (12). NAIC establishes state insurance regulatory standards and best practices and coordinates regulatory oversight (13). In our case, this methodology was helpful to evaluate the severity of injury as it relates to various contributing factors.

One other point of interest found in the CBS claim files was the contributing factors related to each claim. Each claim could have one or more subcategories listed as a potential contributing factor. For instance, a single claim could have listed "Pre-existing Radiculopathy" or "Technical Knowledge of the Proceduralist" as both factors contributing to the claim/injury. The contributing factors were originally coded by registered nurses overseen by a committee of physicians, lawyers, and other analysts (11). This process was completed prior to the initiation of our study.

Narrative descriptions from all cases were reviewed by the authors (R.S., D.K., R.U., E.B.) and 62 cases were judged to be relevant to our study. Our CRICO database review of RA claims excluded cases in which anesthesia provider was not the primary defendant and in which the injury was not related to RA. We also specifically excluded cases related to chronic pain management, as similar analyses of CBS data on this topic have recently been conducted $(7,11)$. We also excluded 7 cases that were claims secondary to negligence on the part of the surgical specialty and not the anesthesia provider as the primary defendant. One such case, for instance, was related to the surgeon inadvertently severing part of the patient's brachial plexus during the procedure and failing to recognize the injury.

\section{Results}

\section{Patient Demographics, Injury Severity, and Payments}

Table 1 shows patient demographics and an overview of all claims chosen for our analysis, including the financial impact. The mean patient age was 46.4 years with a standard deviation of 12.1, ranging from 20 to 74 years. The NAIC outcome severity ranged from 3 (temporary minor injury) to 6 (significant permanent injury) with no score $>6$ or deaths noted. As also shown in the graphical representation (Fig. 1A), the majority of claims were due to permanent minor injuries (NAIC score of
Table 1. Patient demographics and claims overview with contributing factors.

\begin{tabular}{|c|c|}
\hline Cases & n (\%) or USD \\
\hline Cases (total) & 62 \\
\hline \multicolumn{2}{|l|}{ Age } \\
\hline Mean & 46.4 \\
\hline SD & 12.1 \\
\hline Range & $20-74$ \\
\hline \multicolumn{2}{|l|}{ NAIC outcome severity ${ }^{*}$} \\
\hline 1 & 0 \\
\hline 2 & 0 \\
\hline 3 & $6(9.6)$ \\
\hline 4 & $11(17.7)$ \\
\hline 5 & $39(62.9)$ \\
\hline 6 & $6(9.6)$ \\
\hline 7 & 0 \\
\hline 8 & 0 \\
\hline 9 & 0 \\
\hline Settled cases & $10(16)$ \\
\hline \multicolumn{2}{|l|}{ Payment to patient for settled cases (USD) } \\
\hline Median & $\$ 134,000$ \\
\hline Range & $\$ 5,000-\$ 600,000$ \\
\hline Interquartile Range & $\$ 324,423.25$ \\
\hline 95\% Confidence Interval & $\$ 57,903-\$ 387,923$ \\
\hline \multicolumn{2}{|l|}{ Contributing Factors } \\
\hline Technical Knowledge/Performance & $57(92.9)$ \\
\hline Pre-existing Injury/Radiculopathy & $16(25.8)$ \\
\hline Delayed Specialist Consultation & $15(24.2)$ \\
\hline Documentation Error/Missing & $10(16.1)$ \\
\hline Patient Co-morbidity (non-neurologic) & $9(14.5)$ \\
\hline Surgical Trauma & $6(9.6)$ \\
\hline Delayed/Missed Diagnosis & $2(3.2)$ \\
\hline Bleeding/Coagulopathy & 23.2) \\
\hline
\end{tabular}

Abbreviations: NAIC, National Association of Insurance Commissioners; USD = United States Dollars. ${ }^{\star}$ NAIC Severity of Injury Code $^{(12)}: 1=$ Temporary Emotional Injury (Fright or no physical injury), 2 = Temporary Insignificant Injury (Lacerations, contusions, minor scars or rash), $3=$ Temporary Minor Injury (Infection, fall in hospital or fracture set improperly), $4=$ Temporary Major Injury (Burns, surgical material left or drug side effect), $5=$ Permanent Minor Injury (Loss of fingers, loss or damage to minor organs), $6=$ Permanent Significant Injury (Deafness, loss of limb, loss of eye, loss of one kidney or lung), 7 = Permanent Major Injury (Paraplegia, blindness or loss of 2 limbs), 8 = Permanent Grave Injury (Quadriplegia, severe brain damage, life-long care or fatal prognosis), $9=$ Death

5). Out of 62 cases analyzed, 10 were settled (16\%), leaving the majority of 52 cases $(84 \%)$ either denied or dismissed. Payments for settled cases had a median of $\$ 134,000$ and interquartile range of $\$ 324,423.25$. 


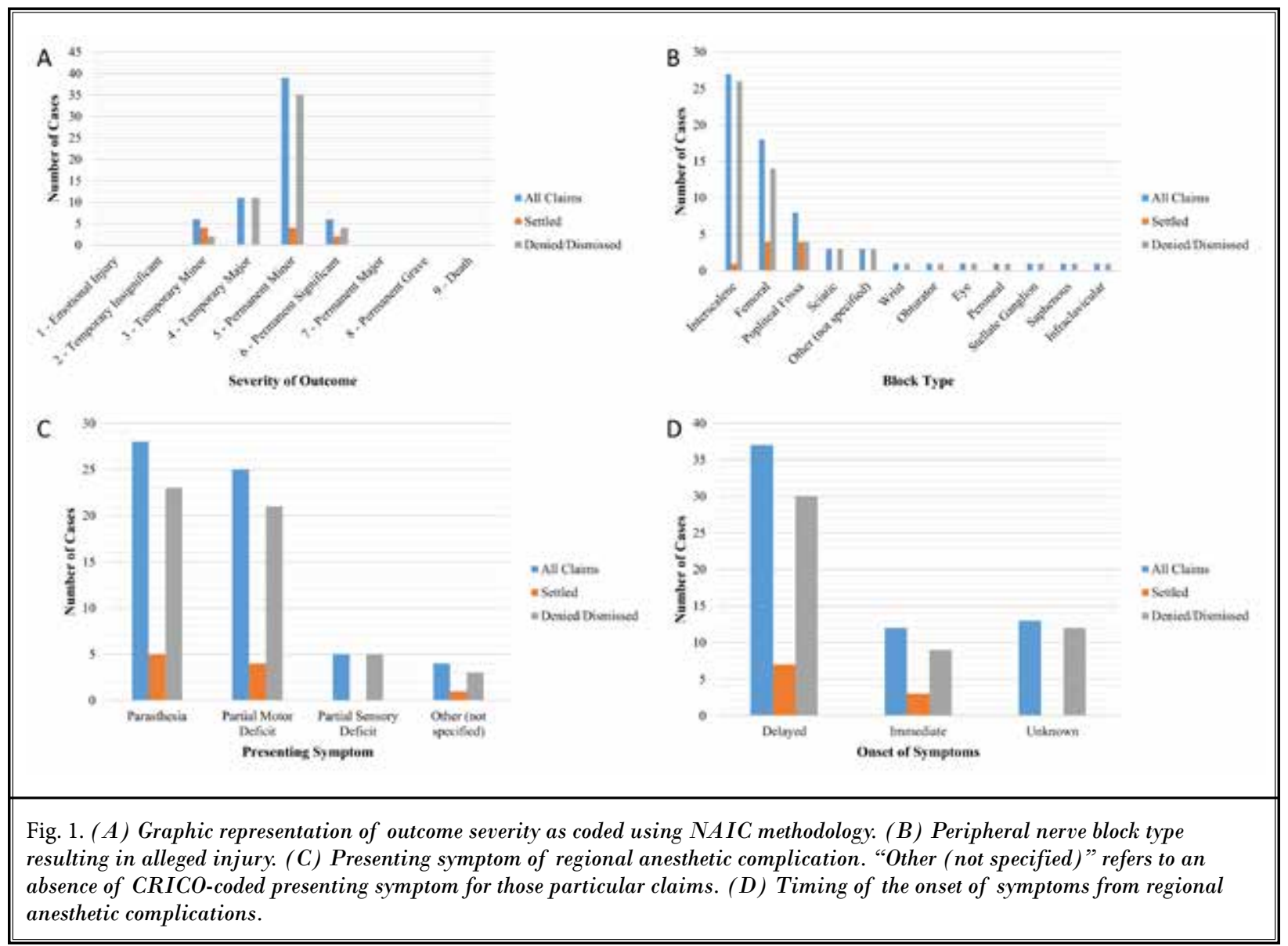

\section{Block Type}

The interscalene block resulted in the most claims at $40 \%$, with femoral blocks at $27 \%$, and popliteal blocks at $12 \%$, as shown in Fig. 1B. Despite interscalene blocks accounting for the majority of claims, only $3.5 \%(n=1)$ of cases resulted in a monetary settlement. Meanwhile, $50 \%$ of alleged popliteal fossa injury claims and $18 \%$ of alleged femoral block injury resulted in monetary settlements. The single settlement associated with the interscalene block involved an extensive surgical repair of an unstable right shoulder. Despite no complications noted during block placement or the surgery, the patient continued to have residual numbness and inability to extend his wrist or fingers, and was ultimately diagnosed with radial nerve palsy and treated with immobilization. The following month, the patient underwent surgical exploration of his right arm in an attempt to release a potentially entrapped radial nerve, but this was unsuccessful as there was no evidence of entrapment or nerve injury-the patient continued immobilization treatment. One year later, the patient showed reasonable recovery, but still maintained a limited extension of his right fingers and thumb-this claim resulted in a settlement. Table 2 includes narrative examples of alleged injuries relating to blocks.

\section{Contributing Factors}

Table 1 shows an overview of all the contributing factors for each claim. "Technical Knowledge/Performance" refers to fault attributed to the proceduralist and occurring during the procedure (i.e., blocking the wrong nerve inadvertently or not aspirating prior to injection). Table 3 includes an example of a settled case relating to the "Technical Knowledge/Performance" of the proceduralist.

The term "Pre-existing Injury/Radiculopathy" refers to prior documented nerve injuries at or near the site of RA. Table 3 includes an example of a settled case relating to "Pre-existing Injury/Radiculopathy." The subcategory "Delayed Specialist Consultation" is when several 
Table 2. Summary of representative cases relating to block type.

\begin{tabular}{|c|c|c|}
\hline $\begin{array}{l}\text { Block- } \\
\text { Type }\end{array}$ & $\begin{array}{c}\text { Settlement } \\
\text { Amount (USD) }\end{array}$ & Narrative \\
\hline $\begin{array}{l}\text { Femoral } \\
\text { Nerve Block }\end{array}$ & $\$ 500,000$ & $\begin{array}{l}\text { The case involved a } 30 \text { year-old patient undergoing a total knee arthroplasty (TKA). The anesthesiologist } \\
\text { reported that the patient had "exquisite tenderness with just ultrasound probe placement," during the block } \\
\text { but never had any paresthesia or shooting pain in the femoral nerve distribution. The patient describes } \\
\text { having " } 10 \text { out of } 10 \text { pain", although this was denied by the assisting nurse who stated that they would have } \\
\text { stopped if the patient was in that much pain. This preoperative block was noted to be unsuccessful and the } \\
\text { team performed a second femoral nerve block post-operatively with no comment on complications. After } \\
\text { the blocks wore off the patient reported decreased quadriceps strength and EMG showed near complete loss } \\
\text { of function of the femoral nerve. Magnetic resonance imaging showed swelling of the femoral nerve from } \\
\text { the inguinal ligament to the area of Hunter's canal. The patient's nerve and muscles ultimately recovered } \\
\text { over a 2-year period, with the orthopedic surgeon noting a complete recovery from the nerve injury. The } \\
\text { patient claimed she still could not stand, squat, or run and that her knee buckled at times. The patient has } \\
\text { been walking with a limp since the procedure. }\end{array}$ \\
\hline $\begin{array}{l}\text { Popliteal } \\
\text { Nerve Block }\end{array}$ & $\$ 600,000$ & $\begin{array}{l}\text { The case involved a patient who underwent a popliteal nerve block which was complicated by common } \\
\text { peroneal neuritis diagnosed several days after injection. The performance of the block was not documented } \\
\text { by the anesthesiologist and the patient developed complex regional pain syndrome which was then treated } \\
\text { with opioids. }\end{array}$ \\
\hline $\begin{array}{l}\text { Interscalene } \\
\text { Block }\end{array}$ & $\begin{array}{l}\text { Denied/ } \\
\text { Dismissed }\end{array}$ & $\begin{array}{l}\text { The case involved a patient with a history of a coronary artery bypass graft undergoing a subacromial } \\
\text { decompression and rotator cuff repair. He underwent a documented uncomplicated interscalene nerve } \\
\text { block prior to the procedure. Post-operative course was uneventful. A month later the patient presented to } \\
\text { the Emergency Department with shortness of breath. Imaging revealed an elevated right hemidiaphragm } \\
\text { with associated pulmonary edema and right lung base infiltrates. He was seen by a pulmonologist and it } \\
\text { was noted that the diaphragm elevation may be from the nerve block. Later it was noted that the diaphragm } \\
\text { injury may have been due to his cardiac surgery and the case was ultimately dismissed. }\end{array}$ \\
\hline
\end{tabular}

signs/symptoms were present to warrant consultation of a specialist (i.e., consulting neurosurgery for new neurologic symptoms). Table 3 includes an example of a "Delayed Specialist Consultation." "Documentation Error/Missing" subcategory typically refers to a missing or an incomplete procedure note but can also refer to discrepancies between what the proceduralist/ staff claimed versus what was actually documented. The other smaller subsets of contributing factors include "Non-neurologic Comorbidities," "Surgical Trauma," "Delayed/Missed Diagnosis," and "Bleeding/ Coagulopathy."

The most common contributing factor present in $92.9 \%$ of claims was "Technical Knowledge/ Performance," followed by "Pre-existing Injury/ Radiculopathy" at $25.8 \%$ and "Delayed Specialist Consultation" at $24.2 \%$. The least cited contributing factors were "Delayed/Missed Diagnosis" and "Bleeding/ Coagulopathy" both at $3.2 \%$, which was identified in 2 claims each.

\section{Symptom Presentation}

Figure $1 \mathrm{C}$ shows the primary presenting symptom for each alleged injury claim. Of all claims, the most frequent presentation was paresthesias at $45 \%$ and with partial motor deficits being the second most common at $40 \%$. Partial sensory deficits only accounted for $8 \%$ of claims. The "Other (not specified)" category of Fig. $1 \mathrm{C}$ refers to claims that did not have a specific code-it was not documented by the clinical taxonomy specialist. The single monetary settlement seen in the "Other (not specified)" column involved a case of generalized lower back and upper thigh pain after a femoral nerve block for a total knee arthroplasty (TKA) in which there was no mention of deficits or paresthesia.

Each claim also documented the onset of symptoms as delayed versus immediate as seen in Fig. 1D. Immediate onset refers to damages occurring at the time of the block or presenting on day of operation. An example of an immediate damage would be wrong-sided block. Delayed onset refers to symptoms presenting after discharge from surgery ranging from days to years. For example, a patient alleged improper performance of a femoral nerve block for a TKA. The patient presented 3 months later after seeing a neurologist who performed electromyography testing, which strongly suggested femoral neuropathy originating in upper third of the affected thigh - the case was ultimately denied as all clinical elements were thought to have been within the standard of care despite the patient's injury. 
Pain Physician: July/August 2019: 22:389-399

Table 3. Summary of representative cases relating to contributing factors.

\begin{tabular}{|c|c|c|}
\hline $\begin{array}{l}\text { Contributing } \\
\text { Factor }\end{array}$ & $\begin{array}{c}\text { Settlement } \\
\text { Amount (USD) }\end{array}$ & Narrative \\
\hline $\begin{array}{l}\text { Technical } \\
\text { Knowledge/ } \\
\text { Performance }\end{array}$ & $\$ 375,000$ & $\begin{array}{l}\text { The case involved a patient who underwent a popliteal fossa nerve block for repair of Haglund's } \\
\text { deformity of the left heel. After confirmation of needle positioning with ultrasound and nerve } \\
\text { stimulation, } 50 \mathrm{~mL} \text { of ropivacaine } 0.5 \% \text { with clonidine was injected around the sciatic nerve at the } \\
\text { level of the popliteal fossa. Nursing notes state that the patient was complaining of pain on injection } \\
\text { but, "not out of the ordinary," for this procedure. An additional } 10 \mathrm{~mL} \text { of ropivacaine } 0.5 \% \text { with } \\
\text { clonidine was injected into the saphenous nerve. It was noted that the proceduralist had to make } \\
\text { several passes to reach the proper location. Post-operatively, the patient developed numbness and } \\
\text { tingling of toes and plantar surface of foot with EMG showing denervation of associated muscles. } \\
\text { Experts noted that the amount of volume administered ( } 50 \mathrm{~mL} \text { ) was not consistent with the standard } \\
\text { of care (usual } 30 \mathrm{~mL} \text { ) and likely contributed to the injury. }\end{array}$ \\
\hline $\begin{array}{l}\text { Technical } \\
\text { Knowledge/ } \\
\text { Performance }\end{array}$ & $\$ 45,000$ & $\begin{array}{l}\text { The case involved the performance of a femoral nerve block for a TKA while the patient was under } \\
\text { general anesthesia. The patient had a post-operative course significant for weakness and ultimately } \\
\text { diagnosed with femoral nerve neuropathy. Although the patient was consented and the procedure } \\
\text { was documented appropriately, there was noted to be a lack of saved imaging or patient feedback } \\
\text { during the performance of the procedure (given the patient was under general anesthesia). The claim } \\
\text { was ultimately settled as they could not rule out an inadvertent intraneural injection. }\end{array}$ \\
\hline $\begin{array}{l}\text { Pre-existing } \\
\text { Injury/ } \\
\text { Radiculopathy }\end{array}$ & $\$ 193,000$ & $\begin{array}{l}\text { The case involved a patient with } 4 \text { out of } 10 \text { ankle pain and tingling after a massage } 6 \text { months prior } \\
\text { who was ultimately diagnosed with tibial nerve neuropraxia. She underwent an anterior tarsal tunnel } \\
\text { release after a popliteal nerve block and had worsening of her pain and tingling post-operatively. This } \\
\text { was partly attributed to the nerve block that the plaintiff expert explained should have been avoided } \\
\text { given pre-existing nerve injury. }\end{array}$ \\
\hline $\begin{array}{l}\text { Delayed } \\
\text { Specialist } \\
\text { Consultation }\end{array}$ & $\$ 75,000$ & $\begin{array}{l}\text { The case resulted from a femoral nerve block for a patient with known multiple sclerosis (MS) who } \\
\text { underwent a TKA with resulting femoral neuropathy. The anesthesiologist evaluated the patient } \\
\text { prior to discharge and thought weakness was secondary to a multiple sclerosis flare. The patient was } \\
\text { discharged without escalation of care for concern of long-term neuropathy. }\end{array}$ \\
\hline $\begin{array}{l}\text { Documentation } \\
\text { Error/Missing }\end{array}$ & $\$ 30,000$ & $\begin{array}{l}\text { The case had an expert anesthesia witness and medical consult both describing no evidence of } \\
\text { negligence towards a patient with persistent quadriceps weakness following a femoral nerve block. } \\
\text { Unfortunately, there was no documentation of the procedure and the case was ultimately settled for } \\
\$ 30,000 \text {. }\end{array}$ \\
\hline $\begin{array}{l}\text { Bleeding/ } \\
\text { Coagulopathy }\end{array}$ & Denied/Dismissed & $\begin{array}{l}\text { The claim was filed due to a "large unappealing bruise" covering much of the patient's neck after an } \\
\text { interscalene block with no long-term complications. }\end{array}$ \\
\hline $\begin{array}{l}\text { Bleeding/ } \\
\text { Coagulopathy }\end{array}$ & Denied/Dismissed & $\begin{array}{l}\text { The case involved a retrobulbar block for cataract surgery that resulted in retinal artery damage - the } \\
\text { patient made a full recovery and the case was ultimately dismissed. }\end{array}$ \\
\hline
\end{tabular}

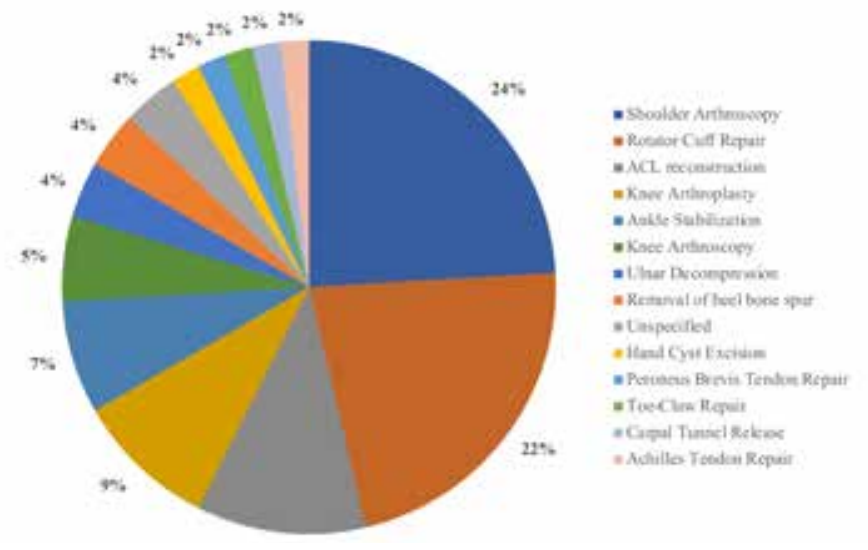

Fig. 2. Surgeries for which a peripheral nerve block was administered that resulted in a closed claim.

\section{Type of Surgery}

Surgery type was abstracted from the narrative summaries and quantified in Fig. 2. The greatest number of claims came from shoulder arthroscopies and rotator cuff repairs, representing $24 \%$ and $22 \%$ of all claims, respectively. A few cases reported a rotator cuff repair using shoulder arthroscopy-in these instances the cases were listed under both categories. Only $7.6 \%$ of shoulder arthroscopies and $8.3 \%$ of rotator cuff repairs resulted in monetary settlements. Knee arthroscopies and arthroplasties represented $5.5 \%$ and $9 \%$ of all claims with $60 \%$ and $33 \%$ resulting in monetary settlements, respectively. 
The "Unspecified" category refers to claims for which the type of surgery was unclear from the narrative.

\section{Discussion}

Our study investigated the nature of, and factors contributing to, patient injury following RA based on the medicolegal claims brought against anesthesia providers that were closed between 2006 and 2016 We used the case summaries provided by CRICO's CBS database. Our analysis shows that most claims were from "permanent minor" injuries followed by "temporary major" injuries. Most claims involved brachial plexus injuries from interscalene blocks performed for shoulder or rotator cuff repairs. Cases with the largest number of monetary settlements, however, involved femoral and sciatic nerve blocks with resulting leg injuries. The largest contributing factor to these injuries was noted to be "Technical Knowledge/Performance" of the regionalist followed by "Pre-existing Injury/ Radiculopathy." Symptom onset from these claims was most likely to be delayed with the leading presenting symptom being paresthesias.

\section{Severity of Claim}

The majority of the claims were "permanent minor" injury. Examples of injuries in this category include loss of fingers and loss or damage to minor organs, for example, injuries that are significant but not completely disabling.

One example of a "permanent minor" injury involved a femoral nerve block performed for a TKA. Table 4 includes sample narratives classified by NAIC severity score. Reliable and consistent data regarding the actual incidence of nerve injury has always been difficult to obtain given the subjectivity of many studies. Major complications resulting in permanent nerve damage has been reported with an incidence of $1.5 / 10,000$, whereas transient or subclinical injuries have been reported to be as high as $8 \%$ to $10 \%(14,15)$.

A study by De Andrés et al (16) analyzed outcomes on 154 patients undergoing peripheral nerve blocks, and the various predictors of patient satisfaction with RA. The authors found that patient attitudes toward RA were favorable $(46.4 \%)$ or indifferent $(45.5 \%)$, with only $6.4 \%$ having a negative attitude. The greatest negative factor was the initial needle puncture for the block. Although the aforementioned study focused on different types of outcomes than our study population, it suggests that patients generally favor or feel neutral toward RA. This may indicate that in the closed claim population dissatisfaction is primarily, if not entirely, weighed on the outcome rather than the use of RA itself. In cases with poor outcomes, however, providers may be able to mitigate the situation by addressing the patient's dissatisfaction regarding the outcome. For instance, providers who are transparent, able to encourage communication, and appropriately apologize if problems arise have a lower incidence of litigation regardless of the procedure outcome $(17,18)$.

\section{Nerves Injured}

Despite having fewer monetary settlements, interscalene block-related claims were still significant in that most cases reported permanent minor injuries. The overall incidence of persistent paresthesias after a brachial plexus block has been estimated at $2 \%$ (19). There are many considerations as to why the brachial plexus (particularly interscalene) block may have resulted in more injuries. Anatomically, the more proximal the nerve block is, the less widely dispersed the nerves are within their respective fascicles $(20,21)$. With interscalene and supraclavicular blocks, for instance, the nerves are more solid with closely spaced fascicles and less stromal tissue in-between them. Intraneural injection into these nerves could have a higher pressure incidence on individual fascicles as well as have a higher likelihood of piercing an individual fascicle. An intraneural femoral nerve block, however, will have more of a pressure-buffer on injection with more stromal tissue in-between fascicles and a larger perineural space. Further, for more peripheral nerves, there is higher possibility of a greater blood supply as nerves communicate with both intrinsic exchange vessels in the endoneurium as well as the extrinsic plexus surrounding the epineurium (4). The extrinsic plexus can penetrate into the intrinsic exchange vessels providing more blood to the nerve-this extrinsic exchange appears more distally in peripheral nerves (4). Again, our results noted that the interscalene block (which is a relatively proximal block in relation to nerve origin) resulted in the majority of closed claims-27 out of 62 cases $(43 \%)$ as shown in Fig. 1B.

No supraclavicular or axillary block resulted in a claim in our database, although there was a single infraclavicular block. In this case, the infraclavicular block was performed prior to a carpal tunnel release procedure that ultimately resulted in complex regional pain syndrome in the distal median nerve distribution. The condition was noted by the orthopedic team to be secondary to the infraclavicular block. However, the 
Pain Physician: July/August 2019: 22:389-399

Table 4. Summary of representative cases relating to injury severity.

\begin{tabular}{|c|c|c|}
\hline $\begin{array}{c}\text { NAIC Severity } \\
\text { Code }\end{array}$ & $\begin{array}{c}\text { Settlement } \\
\text { Amount (USD) }\end{array}$ & Narrative \\
\hline $\begin{array}{l}3 \text { - Temporary } \\
\text { Minor Injury }\end{array}$ & $\$ 5,307$ & $\begin{array}{l}\text { The case involved a patient who developed sciatic injury after a popliteal sciatic block for } \\
\text { Achilles tendon repair. The patient complained of pain after surgery and ultimately found to have } \\
\text { moderate left sciatic axonal neuropathy after an electromyography (EMG) testing by neurology. } \\
\text { Patient's major complaint was sensation loss but ultimately improved with physical therapy. }\end{array}$ \\
\hline $\begin{array}{l}5 \text { - Permanent } \\
\text { Minor Injury }\end{array}$ & Denied/Dismissed & $\begin{array}{l}\text { Based on the clinical summary, the patient recollected experiencing sharp pain and the resident } \\
\text { commented on the difficulty of performing the block despite ultrasound guidance. Despite } \\
\text { the patient's continued complaints of sharp pain, the block was completed and documented as } \\
\text { "uncomplicated" and "without issue or paresthesia." The surgery was without complication but } \\
\text { postoperative course was significant for continued pain and weakness in the patient's proximal leg. } \\
\text { EMG testing confirmed denervation of the left vastus medialis and left vastus lateralis nerves with } \\
\text { computed tomography (CT) showing atrophy of her thigh muscle. }\end{array}$ \\
\hline $\begin{array}{l}5 \text { - Permanent } \\
\text { Minor Injury }\end{array}$ & Denied/Dismissed & $\begin{array}{l}\text { The patient underwent a rotator cuff repair with an interscalene block utilizing a nerve stimulator. } \\
\text { No complications were noted but the patient's postoperative course was significant for brachial } \\
\text { plexus neuropathy, particularly in the ulnar distribution. The patient then underwent multiple } \\
\text { corrective surgeries including nerve transfers and ulnar nerve release. }\end{array}$ \\
\hline $\begin{array}{l}6 \text { - Permanent } \\
\text { Significant Injury }\end{array}$ & Denied/Dismissed & $\begin{array}{l}\text { The case involved a patient who presented for a torn anterior cruciate ligament repair after a } \\
\text { skiing accident. The patient underwent a documented uneventful femoral nerve block prior } \\
\text { to the procedure with placement verified by ultrasound and nerve stimulation. Several days } \\
\text { following the procedure the patient noted difficulty flexing the hip area with associated quadriceps } \\
\text { pain. The patient was evaluated by the anesthesiologist with ultrasound and noted there was no } \\
\text { hematoma or other visible cause of injury to the femoral nerve. The patient was then referred to } \\
\text { pain management several months later and was diagnosed with reflex sympathetic dystrophy for } \\
\text { which the patient was started on neuropathic medications. The orthopedic attending in this case } \\
\text { noted that the particular anesthesiologist was, "horrible and arrogant." }\end{array}$ \\
\hline
\end{tabular}

case was dismissed because of lack of patient follow-up. This pattern may suggest a clinical preference for the practicing regionalist to perform other block types for upper extremity cases-particularly, avoiding interscalene blocks if the alternative block (i.e., supraclavicular, infraclavicular, axillary) can provide adequate surgical coverage and is clinically appropriate.

\section{Contributing Factors}

As with many medicolegal complications, the causes are often complex and multifactorial. The Second American Society of Regional Anesthesia and Pain Medicine (ASRA) Practice Advisory on neurologic complications associated with RA and pain medicine suggested that even with flawless care of otherwise healthy patients by well-trained physicians, complications remain neither completely predictable nor preventable (22). Contributing factors are reported in Table 1. Most cases (93\%) allege negligence in "Technical Knowledge/Performance" of the procedure. Some cases, however, noted specific events such as the wrong site of injection, inadvertent intraneural injection, and pneumothorax as relating to the "Technical Knowledge/Performance" by the regionalist. Table 3 shows a narrative example of such a claim.
Given the wide variability of causes under "Technical Knowledge/Performance" of the procedure, one must remain diligent and up to date on the technical aspect, and also be able to verify and properly assess their performance. This may include continuous practice performance assessments and/or ultrasound usage with saved imaging or video of placement.

The second most cited contributing factor was "Preexisting Injury/Radiculopathy" contributing to $26 \%$ of all claims. Pre-existing nerve injury or radiculopathy are considered relative contraindications to RA by some, owing to the increased risk of injury and difficulty in diagnosing new neurologic perioperative deficits. One theory, the so-called "double crush theory," backed by some clinical evidence suggests that patients who experience a subclinical or obvious injury on top of their pre-existing injury have a higher likelihood of sustaining further long-term damages relating to serial axoplasmic constraints (23). However, when the benefit of a regional anesthetic outweighs the risk (such as in a patient with significant cardiopulmonary disease), a discussion should occur with the patient regarding potential complications and worsening of radiculopathy. It is likely that many of these claims could have been avoided with proper communication and discussion of 
patient's expectations, including a detailed documentation of the conversation (24).

The third most frequent contributing factor, "Delayed Specialist Consultation," refers to cases involving a late consultation of appropriate services such as infectious disease, plastic surgery, or neurology for further evaluation and management of infection, injuries such as large bruising impacting physical appearance, and neurologic damages, respectively.

"Documentation Error/Missing" was reported as a contributing factor in $16 \%$ of claims as seen in Table 1. It is worthwhile to note that the majority of these claims seemed to have followed the standard of care as described in the narrative. Table 3 shows a narrative example involving the contributing factor, "Documentation Error/Missing." It is again important to emphasize the need for detailed documentation in the patient's medical record, as it generally more difficult to defend cases with poor or no documentation (25).

One of the least cited contributing factors was "Bleeding/Coagulopathy." Bleeding from a peripheral nerve block is generally thought to be compressible (with a few exceptions), especially when compared with neuraxial blocks (26). Table 3 shows an example of "Bleeding/Coagulopathy" as a contributing factor. Both of the cases in Table 3 do not appear to be related to negligence toward a patient's particular coagulopathy or anticoagulant medication regimen.

\section{Presenting Neurologic Deficit and Onset}

It is interesting to note that partial motor deficits ( $40 \%$ of claims) and paresthesias ( $45 \%$ of claims) were relatively close in both the number of claims and settlements. Nerve injury from nonmechanical causes typically presents with loss of sensory nerves first, followed by motor. In the case of diabetes, for instance, a patient's longest nerves are affected first (furthest from the cell bodies), which is why one can see a "stocking" loss of sensation in the feet $(27,28)$. These nerves are metabolically demanding given their length and function and are typically first affected by toxic changes in the systemic environment. In these nerves, one often observes deficits in vibration sensation and proprioception first (large A-alpha and beta fibers), which have a higher metabolic demand when compared with $C$ unmyelinated and A-delta fibers linked to pain and autonomic neurons $(27,28)$.

Considering that sensory nerves are more susceptible to injury-prone environments in regional anesthetics (such as local anesthetic neurotoxicity or ischemia), one would expect a much higher number of cases with sensory injuries as compared with motor deficits. This may reflect the outcome of the injury leading to a claim, as patients may be more likely to sue with loss of motor function when compared to loss of sensory function. This makes sense intuitively as loss of quadricep muscle strength in a femoral nerve block would be reasonably more debilitating than loss of anterior thigh and medial leg sensation.

The onset of symptoms was 3 times more likely to be delayed ( 37 claims) than immediate (12 claims). Much of the academic discussion regarding delayed presentation is anecdotal or stems from case studies. Immediate complications, compared to delayed ones, are typically recognized while the surgical patient is surrounded by health care providers and are thus addressed in a timelier fashion, potentially resulting in fewer claims. Immediate injuries may also be attributed to a normal course of the regional anesthetic and the injury may not be recognized until much later. Both of these factors may contribute to complications being more likely to present as delayed symptoms. Patients are commonly sent home in ambulatory procedures without full recovery from their block. Even ASRA has recognized that some patients are appropriate to be discharged home with continuous peripheral nerve catheters (29). The risk is that complications that could have been recognized during the immediate recovery period are then potentially missed. Therefore, it is often not feasible to properly assess full recovery in the immediate postoperative period, as many ambulatory orthopedic procedures requiring blocks often have splints or casts postoperatively, and furthermore may have some portion of deficit attributed to recovery from the tourniquet (30).

Given the majority of claims presenting delayed symptoms, postdischarge follow-up to assess complete recovery from RA may be warranted. If there is reported nerve injury, the patient may benefit from a timely diagnosis and early intervention. Furthermore, reassurance may decrease the patient's anxiety associated with the injury and ultimately improve patient satisfaction and decrease the likelihood of litigation.

\section{Type of Surgery}

The type of surgery involved in the claims analyzed, as shown in Fig. 2, correlates well with the block performed. Blocks involving the brachial plexus, particularly interscalene blocks, have led to the most claims. It is not surprising then that most claims were associated 
with shoulder or rotator cuff repair surgeries, as the interscalene block is the primary block type for adequate shoulder coverage and can be used as a sole anesthetic (31). Knee arthroplasty and anterior cruciate ligament repair followed shoulder surgeries in number of claims, which correlates with the large number of femoral blocks in our dataset.

\section{Limitations}

Although closed claims analysis can offer insight into low-frequency adverse events, there are many inherent limitations (32). Closed claims are not all encompassing to patients who suffer a complication, so one cannot determine the incidence of a particular injury. They are, furthermore, based on retrospective data analysis, making it difficult to comment on the causeeffect relationship. The small sample size also limits the ability to charge high power studies in detecting clinical differences and associations with specific comorbidities or techniques (8). We are also limited by the information coded by the data proprietor given the inherent nature of closed claims analysis-leaving us unable to independently verify coded fields or have access to primary records. There was also limited information related to regional anesthetic techniques and medications used that would have helped explore further relationships between the procedure and cause for litigation. Specifically, there are inconsistent data on the technique used (ultrasound, nerve stimulation), or the amount and type of local anesthetic injected. These have all been implicated as risk factors for RA-related nerve injury, and further evaluation was limited in this study secondary to a lack of coding or information in the CRICOprovided narrative for each file (19). Regarding the use of ultrasound guidance, it is important to note that the impact on the incidence of peripheral nerve injury is still unclear (33), and some of its short-comings include suboptimal visualization of deep small structures, axial or spinal structures when an acoustic shadow artifact is produced by bone that contains a high attenuation coefficient, and thin needles or needles inserted at a steep angle. The study also lacks independent reliability assessments by board-certified anesthesiologists who were practicing at the time, although the authors reviewed all case summaries included in this study.

\section{Conclusions}

RA has emerged as a valuable strategy in both acute and chronic pain states. Although the techniques have evolved over the past 2 decades, including nerve stimulation and ultrasound guidance, complications can be longstanding and devastating. The present investigation revealed that the greatest number of claims with payment were related to brachial plexus injuries associated with interscalene blocks performed for shoulder or rotator cuff repairs, and femoral and sciatic nerve blocks with resulting lower extremity injuries. In summary, patients with existing nerve injury or radiculopathy may warrant alternative techniques or greater emphasis during informed consent on the increased risk of injury. A patient undergoing an upper extremity procedure with pre-existing brachial plexus radiculopathy, for instance, may warrant avoidance of RA altogether. If RA is unavoidable then perhaps a supraclavicular block may decrease the risk of complications when compared to an interscalene block. Furthermore, there needs to be consistent transparency in communication and a frank discussion should an adverse outcome occur-not only for professional integrity, but also as it carries a lower incidence of litigation regardless of severity $(17,18)$. Integrity in professional practice also includes discussion of risks and expectations with all procedures and consistent proper documentation-these contributions, previously described, and seen in this study may decrease litigation (24). We have seen that most injuries related to claims are delayed in their presentation and a timely diagnosis and intervention cannot be pursued if the injury is not known to the clinician. Postdischarge follow-up may be warranted to provide best care for patients and avoid long-term injury, decrease litigation, and ultimately improve care quality and patient satisfaction. Clearly, there are opportunities for improvement in regional anesthesia practices with a continued focus on safety and evidence-based care. 


\section{References}

1. Cozowicz C, Poeran J, Memtsoudis S. Epidemiology, trends, and disparities in regional anaesthesia for orthopaedic surgery. Br J Anaesth 2015; 115:ii57-ii67.

2. Fleischut PM, Eskreis-Winkler JM, Gaber-Baylis LK, Giambrone GP, Faggiani SL, Dutton RP, Memtsoudis SG. Variability in anesthetic care for total knee arthroplasty. Am J Med Qual 2014; 30:172-179.

3. Danninger T, Stundner O, Rasul R, Mazumdar M, Gerner P, Memtsoudis SG. Factors associated with hospital admission after rotator cuff repair: The role of peripheral nerve blockade. J Clin Anesth 2015; 27:566-573.

4. Jeng C, Torrillo T, Rosenblatt M. Complications of peripheral nerve blocks. $\mathrm{Br}$ J Anaesth 2010; 105:i97-i107.

5. Arbona FL, Khabiri B, Norton JA. Ultrasound-guided regional anesthesia: $A$ practical approach to peripheral nerve blocks and perineural catheters. In: Additional upper extremity peripheral nerve blocks. 1st ed. Cambridge, UK: Cambridge University Press; 2011:78-82.

6. Wulf $\mathrm{H}$. Nerve damage in regional anesthesia-A complication and many possible causes. Anasthesiol Intensiumed Notfallmed Schmerzther 2012; 47:318-319.

7. Abrecht CR, Brovman EY, Greenberg P, Song E, Rathmell JP, Urman RD. A contemporary medicolegal analysis of outpatient medication management in chronic pain. Anesth Analg 2017; 125:1761-1768.

8. Weingart SN. CRICO home. www.rmf harvard.edu/About-CRICO. Accessed October 9, 2018.

9. Lee LA, Posner KL, Kent CD, Domino KB. Complications associated with peripheral nerve blocks. Int Anesthesiol Clin 2011; 49:56-67.

10. Chui J, Murkin JM, Posner KL, Domino KB. Perioperative peripheral nerve injury after general anesthesia. Anesth Analg 2018; 127:134-143.

11. Abrecht CR, Greenberg P, Song E, Urman RD, Rathmell JP. A contemporary medicolegal analysis of implanted devices for chronic pain management. Anesth Analg 2017; 124:1304-1310.
12. Acerbe-Aualrme N, Kremer K. Medical malpractice claims investigation. Healthc Qual 1998; 20:45.

13. National Association of Insurance Commissioners. Medical Professional Liability Insurance. www.naic.org/index_about. htm. Accessed October 9, 2018.

14. Auroy Y, Benhamou D, Bargues L, Ecoffey C, Falissard B, Mercier FJ, Bouaziz H, Samii K. Major complications of regional anesthesia in France: The SOS Regional Anesthesia Hotline Service. Anesthesiology 2002; 97:1274-1280.

15. Liu SS, Zayas VM, Gordon MA, Beathe JC, Maalouf DB, Paroli L, Liguori GA Ortiz J, Buschiazzo V, Ngeow J, Shetty T, Ya Deau JT. A prospective, randomized, controlled trial comparing ultrasound versus nerve stimulator guidance for interscalene block for ambulatory shoulder surgery for postoperative neurological symptoms. Anesth Analg 2009; 109:265-271.

16. De Andrés J, Valía JC, Gil A, Bolinches R. Predictors of patient satisfaction with regional anesthesia. Reg Anesth 1995; 20:498-505.

17. Advisory Board. Which patients are most likely to file malpractice suits? www.advisory.com/daily-briefing/2013/02/05/ which-patients-are-most-likely-to-filemalpractice-suits. Accessed October 9, 2018.

18. Rhodes TW. Some legal thoughts on the unhappy patient. Facial Plast Surg Clin North Am 2008; 16:245-248.

19. Bajaj P. Regional anaesthesia in the patient with pre-existing neurological dysfunction. Indian J Anaesth 2009; 53:135-138.

20. Bonnel F, Rabischong P. Anatomie et systématisation du plexus brachial de ladulte. Anat Clin 1980; 2:289-298.

21. Bonnel F. Microscopic anatomy of the adult human brachial plexus: An anatomical and histological basis for microsurgery. Microsurgery 1984; 5:107-117.

22. Neal JM, Barrington MJ, Brull R, Hadzic A, Hebl JR, Horlocker TT, Huntoon MA, Kopp SL, Rathmell JP, Watson JC. The second ASRA practice advisory on neurologic complications associated with regional anesthesia and pain medicine. Reg Anesth Pain Med 2015; 40:401-430.

23. Upton A, Mccomas A. The double crush in nerve-entrapment syndromes. Lancet 1973; 302:359-362.

24. Bartlett EE. Physician stress management: A new approach to reducing medical errors and liability risk. J Healthc Risk Manag 2002; 22:3-7.

25. Thomas J. Medical records and issues in negligence. Indian J Urol 2009; 25:384.

26. Li J, Halaszynski T. Neuraxial and peripheral nerve blocks in patients taking anticoagulant or thromboprophylactic drugs: Challenges and solutions. Local Reg Anesth 2015; 8:21-32.

27. Reevers AG, Swenson RS. Disorders of the nervous system: A primer. Chapter 9: Sensory system evaluation. Dartmouth Medical School. www.dartmouth.edu/ dons/part_1/chapter_9. html. Accessed October 9, 2018.

28. University of Washington. Peripheral neuropathy. courses.washington.edu/ conj/neuron/peripheralNeuropathy. htm. Accessed October 9, 2018.

29. American Society of Regional Anesthesia and Pain Medicine. Pain relief after surgery. www.asra.com/page/42/painrelief-after-surgery. Accessed October 9 , 2018.

30. Mariano E. Sending patients home after regional anesthesia procedures. https:// medschool.ucsd.edu/som/anesthesia/ divisions/regional-anesthesia/Documents/sending-patients-home-regional-anesthesia-procedures.pdf. Accessed October 9, 2018.

31. Hadzic A, Williams BA, Karaca PE, Hobeika P, Unis G, Dermksian J, Yufa M, Thys DM, Santos AC. For outpatient rotator cuff surgery, nerve block anesthesia provides superior same-day recovery over general anesthesia. Anesthesiology 2005; 102:1001-1007.

32. Cheney FW. The American Society of Anesthesiologists Closed Claims Project. Anesthesiology 1999; 91:552-556.

33. Neal JM. Ultrasound-guided regional anesthesia and patient safety: Update of an evidence-based analysis. Reg Anesth Pain Med 2016; 41:195-204. 
